\title{
Smart City: IOT Based Prototype for Parking Monitoring and Management System Commanded by Mobile App
}

\author{
Durga Devi TJB \\ Department of \\ MCA KSRCE \\ Tiruchengode, India \\ Email: durgatjb@gmail.com
}

\author{
Dr. A.Subramani \\ Department of Computer \\ ScienceGovt Arts College \\ Dharmapuri, India \\ Email: subramani.appavu@gmail.com
}

\author{
Dr. Vijender Kumar Solanki \\ Department of IT \\ Institute of Technology \& Science \\ Ghaziabad, UP, India \\ Email: spesinfo@yahoo.com
}

\begin{abstract}
This paper introduces a prototype for IoT based smart parking system that attempts to automate vehicle parking system that leads to minimize vehicle parking problem. Traffic congestion caused by vehicles is an alarming problem at a global scale and it has been growing exponentially. Searching for a parking space and buying tickets for their parking from ticketing machines is a routine activity for many people in cities around the world. We propose a prototype that would monitor the parking spaces availability through the emerging Internet of Things (IoT) technology and automate the ticketing system from smart phones by mTicketing system.
\end{abstract}

Index Terms-Parking monitoring, Parking reservation, Internet of Things (IoT), Smart Mobile App

\section{INTRODUCTION}

Internet of Things is the interconnectivity between things, people and cloud services via internet which enables new business models. As a result of these communications, huge volumes of data are being intelligently generated, and the generated data is sent to cloud based server via internet and that data isbeing processed and analyzed, resulting in meaningful and timely actions for monitoring the vehicle parking.

The major problem that is emerging recently at a global scale and growing exponentially is the traffic congestion problem caused by vehicles. Amongst that car parking becomes the predominant contributor and is still becoming a major threat with increase in number of vehicles and very confined parking spaces in urban cities. Searching for a parking space and buying tickets for their on street parking from ticketing machines is a routine activity for many people in cities around the world.

A study on this search for parking space says it burns about one million barrels of the world's oil every day. The problem will worsen as the population continues to urbanize and without a well-planned on-street car parking mechanism. According to a report, Smart Parking could result in 2,20,000 gallons of fuels saving till 2030 and approx. $3,00,000$ gallons of fuels saved by 2050 , if implemented successfully.
Smart Parking system obtains the information such as availability of the parking space, the time when the vehicle parked in, the time when the parking vehicle left. It involves the smart sensors that could be fixed in street lights for every parking space, collection of real-time data, a web-based portal to monitor the parking spaces and a mobile app which will enable user to reserve a parking space and make online payment from their mobile app for their parking.

Thus deployed, this smart parking reduces the need for people to needlessly circle city blocks searching for parking and that results in reduction of car emissions. It also helps the cities in controlling the non-payment parking.

\section{Related Work}

As the technology changes with time, the source to generate information for car parking system has also been changed. Today, the wireless sensor networks are the major sources of generating diverse information. Various approaches has been carried out to find a better way for smart parking system and these include technologies like Wireless networks, GSM based parking management, image processing technique, RFID, number plate recognition and so on.

In this paper we proposed an approach to monitor the demarcated on-street car parking system based on IoT technology and help the public to reserve their parking spaces through a mobile App. We have considered major factors like effective elimination of need for search of parking spaces, effective parking monitoring system and cost effectiveness. The mobile application would be much more useful in terms of user-friendliness, quick and simple way to reserve the parking spaces with online payment facility. The parking monitoring is based on IoT which streams the live data to the cloud based server. When it comes to IoT, the most primary thing would be the source, the sensors to generate information. And, the biggest barrier would be the cost involved in installing the same. Considering the cost effectiveness, in our approach the wireless sensors could be installed in the street lights and hence no separate infrastructure set up is required. 


\section{PRoposed PRototype}

\section{A. Basic Architecture}

Below is the proposed architecture that puts forth the ideology behind.

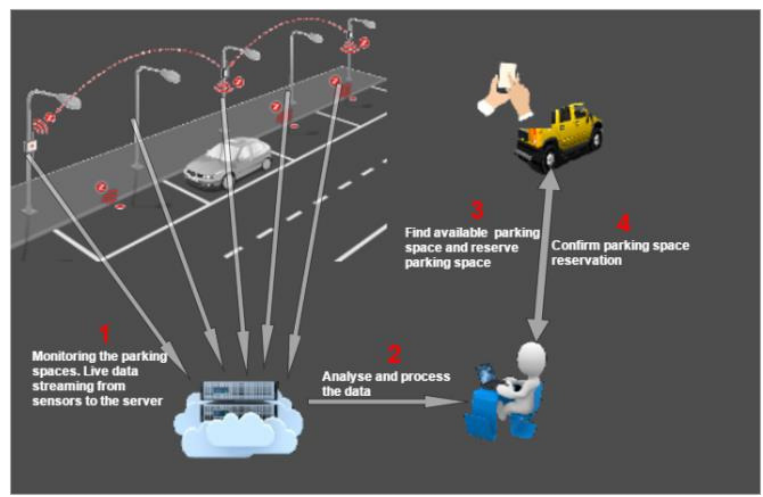

As the first step, the sensors which help us to detect the vehicle occupancy state will stream the live data to the cloud based server. The sensor transmits the vehicle's geolocation, the time it arrived at the parking space and the time when the vehicle leaves the parking space. The parking management system monitors the parking space with the help of live streaming from the cloud based sever. The public then could use the mobile app that communicates with the parking management system to know the availability of parking spaces when they are nearby a parking area.

This would drastically reduce the time for searching a parking space. Also, since the user could buy tickets for their parking from within the app it could be a real hassle-free parking experience for them. It would also result in preventing accidents as the user while parking would have their focus on finding a parking space rather than focusing the road. On the other side it would help the local authority to monitor the occupancy and payment yielding in reduction of nonpayment users benefiting revenue generation for the city.

\section{B. Data Generation}

The proposed architecture is primarily focused on stream lining the demarcated on-street parking system where every parking space will be clearly identified. There are multiple approaches for the sensor installation and we have chosen to install the wireless sensors in street lights considering the cost effectiveness. Each sensor will be configured with a geo fence based on the geo location of every parking space. The parking availability/occupancy state for a particular parking space will be detected by sensor based on the geolocation of the parking space.

Through web socket connection, the sensor will start the live streaming of data to the data center whenever an event takes place in a parking space. Each sensor will be associated with an ID. The data such as the sensor id, the parking space status whether it is available or occupied, the geo-location of the parking space, the time of arrival or departure based on the nature of event will be transmitted to the server through socket connection.

\section{Cloud Based Server}

The data generated through the sensors will be transmitted to the cloud based server through the socket connection. The web socket keeps the connection alive and when parking space state changes the data will be streamed to the cloud based server instantly.

The cloud based server could be typically an Amazon elastic server which is easy to scale up and scale down based on the rate of generation of data. Also, this cloud based server acts as the source of data for the parking management system.

\section{Parking Monitoring \& Management System}

The parking monitoring and management system is connected to the cloud based server. The communication between them happens through the socket connection.

\section{i. $\quad$ Parking Monitoring System}

The system monitors all the demarcated on-street parking space states by means of data it has from the data server. The total number of parking spaces, the total number of available parking spaces, and the total number of occupied parking spaces can be monitored. Also, the states of parking spaces can be rendered in Google maps as the parking spaces geolocations are also been transmitted to the system from the data server.

\section{ii. Parking Management System}

The parking management system communicates between the data server and the mobile application to help the users to reserve the parking spaces. The system is correlated with a fixed pricing schema. It comes with a structure that has fixed prices on hour basis. This system benefits in terms of revenue generation for the smart city. The users who are parking without payment could be found easily by using this system. The local authority could be provided with a mobile app who can easily track the non-payment parking spaces.

\section{E. Mobile App}

Today the technology is all around mobility as the number of mobile users has increased and increasing enormously. The technology solutions are all around 
mobile. And following the same, the mobile app is the smartest way for a hassle-free parking solution to the users. The users can look around for a free parking space and start their reservation as soon as they arrive at the parking space. This will tremendously reduce the parking searching time and helps grow our city green as the pollution will also be reduced obviously.

The mobile app communicates closely with the parking management system to render the live states of parking spaces. The users can see the occupied parking spaces and the available parking spaces in Google map when a user is nearby that zone. And when the user occupies a free parking space, the sensor will detect it and notify the same to the parking monitoring and management system via the cloud based server through web socket communication.

The user can then reserve the parking space after arriving at the spot from the mobile app. Based on the pricing schema structured by parking management system rate card on hour basis will be shown to the users. Then user can proceed with the online payment facility. Once the transaction is successful the parking will be confirmed to the users.

If the user has not vacated before the parking time allotted, the user will be notified through their mobile app when the hours for parking is about to expire to vacate the parking space. The parking management system keeps track of the parking spaces and hence when a vehicle overstays in a parking space they can easily spot it and he local authority can proceed with the next steps. Once the vehicle leaves the parking space the sensor will notify the system about the parking state change instantly.

\section{CONCLUSION}

In this paper we proposed a prototype for providing a better solution for smart city mainly focusing on assisting the public for hassle-free parking and which also helps the local government in revenue generation.

Future work is planned to perform experiments on the ideas discussed.

\section{REFERENCES}

[1] Baratam. M Kumar Gandhi, M.Kameswara Rao, "A Prototype for IoT based Car Parking Management System for Smart Cities", Indian Journal of Science and Technology, Vol 9(17), May 2016

[2] Snehal Shinde, Shilpadevi Bhagwar, Snehal Pharate, Vaishali Paymode, "Prediction of Parking Availability in Car Parks using Sensors and IOT: SPS", International Journal of Engineering Science and Computing, Volume 6 Issue No 4, April 2016

[3] Vishwanath Y, Aishwarya D Kuchalli, Debarupa Rakshit, "Survey paper on Smart Parking System based on Internet of Things", International Journal of Recent Trends in Engineering \& Research (IJRTER), Volume 02, Issue 03, March - 2016

[4] Faiz Shaik, Nikhilkumar B.S, Omkar Kulkarni, Pratik Jadhav, Saideep Bandarkar, "A Survey on Smart Parking System", International Journal of Innovative Research in Science, Engineering and Technology, Vol. 4, Issue 10, October 2015

[5] Thanh Nam Pham, Ming-Fong Tsai, Duc Binh Nguyen, Chyi-Ren Dow, Der-Jiunn Deng, "A cloud based Smart-Parking System based on Internet-of-Things Technologies", IEEE Access, Special Section on Emerging Cloud-based Wireless Communication and Networks, Vol. 3, September 2015

[6] Aditya Gaur, Briyan Scotney, Gerard Parr, Sally McClean, "Smart City Architecture and its Applications based on IoT", The 5th International Symposium on Internet of Ubiquitous and Pervasive Things, Elsevier, Procedia Computer Science 52 (2015) 1089 - 1094, 2015

[7] Zhanlin Ji, Ivan Ganchev, Mairtin O Droma, Li Zhao, Xueji Zhang, "A Cloud-Based Car Parking Middleware for IoT-Based Smart Cities: Design and Implementation", Sensors 2014, 14, 22372-22393; doi:10.3390/s141222372, ISSN 1424-8220, November 2014

[8] Prof D. J Bonde, Rohit S. Shende, Ketan S. Gaikwad, Akshay S. Kedari, Amol U. Bhokre, "Automated Car Parking System Commanded by Android Application", International Journal of Computer Science and Information Technologies, Vol. 5 (3), 2014 